\title{
LA IRRESPONSABILIDAD DEL REY: EVOLUCIÓN HISTÓRICA Y REGULACIÓN ACTUAL
}

CARMEN FERNÁNDEZ-MIRANDA CAMPOAMOR Profesora Titular de Derecho Constitucional 


\section{SUMARIO}

1. La sacralidad de la Persona del Rey. 2. La inviolabilidad de la persona del REY; SU IRRESPONSABILIDAD. 3. IRRESPONSABILIDAD Y REFRENDO EN LA EVOLUCIÓN DE LA Monarquía: de la Monarouía absoluta a la Monarouía Constitucional; de la Monarouía Constitucional a la Monarouía Parlamentaria. 4. El refrendo en la Constitución Española de 1978: 4.1. Concepto 4.2. Sujetos 4.3. Objeto y modalidades. - 4.4. Excepciones 4.5. Efectos. 5. ReCAPITULACIÓN. 


\title{
LA IRRESPONSABILIDAD DEL REY. EL REFRENDO: EVOLUCIÓN HISTÓRICA Y REGULACIÓN ACTUAL'
}

\author{
POR \\ CA:RMEN FERNÁNDEZ-MIRANDA CAMPOAMOR \\ Profesora Titular de Derecho Constitucional
}

En la Constitución Española de 1978, el Rey es el Jefe del Estado; es decir, es el titular de un Órgano constituido que recibe el nombre de

1 Bibliografía: STC 5/1987, de 27 de enero; doctrina ratificada en STC 8/1987, de 29 de enero.

Aragón ReYes, M., Dos estudios sobre la Monarquía Parlamentaria, Civitas, Madrid, 1990. Bassols ComA, M., "Instituciones administrativas al servicio de la Corona: la dotación de la Corona, la Casa de S. M. El Patrimonio Nacional», en Lucas Verdú, P. (comp.), La Corona y la Monarquía Parlamentaria en la Constitución de 1978, Facultad de Derecho, Universidad Complutense, Madrid, 1983. CoLmeIRo, Elementos de Derecho Político y Administrativo de España, 3. ${ }^{a}$ ed., Imprenta de F. Martínez García, Madrid, 1876. Coronas GonzÁlez, S., "La responsabilidad de los Ministros en la España Constitucional», en Anuario de Historia del Derecho Español, Madrid, 1986. De Esteban, J., y González-Trevijano, P. J., Curso de Derecho Constitucional Español, tomo III, Servicio de Publicaciones, Facultad de Derecho, Universidad Complutense, Madrid, 1994. Fusl, J. P., y PALAFOX, J., España: El desafío de la modernidad, Espasa-Calpe, Madrid 1997.-Garcia Canales, M. La Monarquía Parlamentaria Española. Tecnos. Madrid, 1991, y «El refrendo en las Monarquías», en REP n. ${ }^{\circ}$ 212, Madrid, 1977. Garcia Gallo, A., Manual de Historia del Derecho Español. Antología de Fuentes, Artes Gráficas y Ediciones, Madrid, 1959. HeRRERo y R. DE Miñón, M., "Artículo 64. Refrendo de los actos Reales" y "Artículo 56. El Rey", en ALZAGA, O. (dir.), Comentarios a la Constitución Española de 1978, tomo V, Cortes Ge- 
"Corona". No es el soberano, lo es el pueblo. No forma parte del Poder Ejecutivo, que pertenece al Gobierno; éste sólo precisa para existir y subsistir, la confianza del Parlamento, elegido por sufragio universal.

Pese a esta formulación novedosa, nuestra Constitución mantiene determinados atributos de la Monarquía cuyo origen se pierde en el tiempo: la inviolabilidad y la irresponsabilidad que, junto a la transmisión hereditaria y el ejercicio vitalicio del cargo, permanecen como pilares vertebrales de la institución. En este estudio se pretende abordar el análisis de la inviolabilidad y la irresponsabilidad y los mecanismos jurídicos creados por el Estado democrático que hacen posible la aceptación de la institución monárquica sin que ésta renuncie a los caracteres que impregnan su esencia.

\section{LA SACRALIDAD DE LA PERSONA DEL REY}

El carácter de persona sagrada y, en consecuencia -como dice el adagio clásico - «que no puede obrar mal» o "que no puede hacer injusticia" alude a la consideración de que el Rey es el representante de Dios.

Esta idea surge en las primeras civilizaciones como producto de la necesidad humana de divinizar lo poderoso. Como dice Kelsen, en la conciencia del hombre primitivo el orden de su vida en común tiene

nerales, Edersa, Madrid, 1997. Jellineck, G., Teoría del Estado, Albatros, Buenos Aires, 1970. KeLsen, H., Teoría General del Derecho y del Estado, UNAM, Méjico, 1969, y Teoría General del Derecho, Editora Nacional, Madrid, 1979. López GuerRA, L., "Las funciones del Rey y la institución del refrendo", en TORRES DEL MORAL, A. y GÓmEz SANCHez, Y. (dir.), Estudios sobre la Monarquia, UNED, 1995. MENÉndez ReXACH, A., La Jefatura del Estado en el Derecho Público Español, INAP, Madrid, 1979. Nieto, A., Los primeros pasos del Estado Constitucional, Ed. Ariel-Derecho, Barcelona, 1996. Pérez Serrano, N., Tratado de Derecho Político, Civitas, Madrid, 1979. Ruiz del Castiulo, C., Manual de Derecho Político, Ed. Reus, Madrid, 1959. Santamaría de Paredes, V., Curso de Derecho Político, Ricardo Fe, Madrid, 1909, 8. ${ }^{\circ}$ ed. Solozábal Echavaraí, J. J., La sanción y promulgación de la ley en la Monarquía Parlamentaria, Tecnos, Madrid, 1987. Tenorio Sanchez, P., y Gonzalo González, M., «La Corona en los discursos parlamentarios del Rey", en Torres del Moral, A. y Gómez Sánchez, Y. (dir.), Estudios sobre la Monarquia parlamentaria en la Constitución Española, UNED, 1995. Torres del Moral, A., Principios de Derecho Constitucional Español, Il tomo, Servicio de Publicaciones de la Facultad de Derecho, Universidad Complutense, Madrid, 1992, 3. ${ }^{\circ}$ ed., y Constitucionalismo Histórico Español, Átomo Ed., Madrid, 1986. Diferentes "voces» en Enciclopedia Jurídica Básica, Civitas, Madrid, 1995. 
origen divino o mágico; y este origen supraterreno de la norma, revierte en la creencia del origen divino del titular del poder que es un ser de naturaleza diferente al resto de los humanos, representante o instrumento de la divinidad ${ }^{2}$.

Esta concepción nace en la práctica en las organizaciones políticas de Oriente ${ }^{3}$ y de ahi se transmite a Occidente siendo permanente $^{4}$ atributo de la Monarquía hasta que desaparece definitivamente con la implantación del Estado democrático de nuestros días.

En el marco de la historia constitucional española, en las Constituciones de 1812 (art. 168), 1837 (art. 44), 1845 (art. 42) y 1876 (art. 48), se dice que "La persona del Rey es sagrada e inviolable y no está sujeta a responsabilidad».En la Constitución de 1869 (art. 67) se suprime el adjetivo de sagrada y, como en la actual (art. 56,3) se califica a la persona del Rey como «inviolable y no sujeta a responsabilidad»; ello es debido a que cada.Norma responde a planteamientos distintos.

La Constitución de 1812 como tributo obligado al sistema político que quiere sustituir, en su afán por buscar legitimidad histórica a la labor constituyente. De ahí la incoherencia de establecer que la soberanía pertenece a la Nación quien acepta a Fernando VII como «Rey de las Españas»(art. 179) y, al mismo tiempo, respetar el tradicional origen divino de la institución procedente de "las antiguas leyes fundamentales de la Monarquía" que conlleva admitir la sacralidad de la persona del Rey5.

2 Teoría General del Estado, cit. p. 421.

3 En la Biblia el Rey es un ungido, portador del espíritu de Dios y de la esperanza del pueblo; ha de defenderlo, guiarlo y hacer prevalecer la justicia. El gesto de David ante el Rey Saúl, indefenso, manifiesta veneración a la sacralidad de la función que ejerce: "No le mates. No se puede atentar impunemente contra el ungido del Señor". 1. ${ }^{\circ}$ Libro de Samuel, 26-2.

4 La consagración del Rey fue una práctica de los Godos que pasó a los Reinos de León y Castilla...era el complemento y sanción religiosa del acto de la coronación y un medio de afirmar la potestad humana con intervención de la autoridad divina. En Colmeiro. Elementos de Derecho Político y Administrativo de España, 3." ed., Imprenta de F. Martínez García, Madrid, 1870, p. 56.

5 El Preámbulo dice así: "Las Cortes Generales y Extraordinarias de la Nación Española, bien convencidas... de que las antiguas Leyes Fundamentales de esta Monarquía, acompañadas de las oportunas providencias y precauciones que aseguren de un modo estable y permanente su entero cumplimiento, podrán llenar debidamente el grande objeto de promover la gloria, la prosperidad y el bien de toda la Nación, decreta la siguiente Constitución politica para el buen gobierno y recta administración del Estado".

Sobre este tema, ver Fusı, J. P., y PALAFOX, J., España: el desafío de la modernidad, cit. p. 54 . 
En las Constituciones de 1837, 1845 y 1876, de forma coherente, pues en ellas subsiste la soberanía regia aunque compartida con las Cortes ${ }^{6}$. En la Constitución de 1869, como en la actual, al considerarse al pueblo el origen de todo poder?.

No cabe duda que a lo dicho corresponde la denominación de «Rey por la gracia de Dios» utilizada, obviamente en la Monarquia absoluta, y en la mayoria de nuestras Constituciones históricas ${ }^{8}$.

\section{LA INVIOLABILIDAD DE LA PERSONA DEL REY. SU IRRESPONSABILIDAD}

Al atributo de persona "sagrada" se añade, como primera consecuencia jurídica, el calificativo de «inviolable» o persona que no puede ser censurada ni acusada ni, en consecuencia, sometida a juicio; es decir, persona contra la que el Estado no puede ejercer la coacción legítima. En suma, la inviolabilidad significa una especial protección jurídica de la vida y del honor del Monarca9.

Esta concepción es desarrollada en el pensamiento medieval según el cual el Rey, como creador del orden jurídico, como fuente de justicia o Tribunal último, está sometido a la «vis directiva» de la ley pero no a su "vis coactiva». No es parte del Estado sino que está fuera y por encima de él10.

- En relación a la Constitución de 1837, creo muy fundamentada la tesis defendida por Torres del Moral en cuanto a que es la soberanía compartida, y no la soberanía nacional, la que informa dicha Norma. En Constitucionalismo histórico Español, cit. p. 72.

7 Artículo 67. En el artículo 32, a su vez, se dice: "La soberania reside esencialmente en la Nación, de la cual emanan todos los poderes"

8 Así las Constituciones de 1812, "Fernando VII Rey de España por la gracia de Dios y la Constitución"; 1837, 1845 y 1876 (vigente hasta 1931): “...Alfonso XII, por la gracia de Dios, Rey Constitucional de España... que en unión y de acuerdo con las Cortes del Reino... hemos venido en decretar y sancionar la siguiente Constitución"; no así las Constituciones de 1856: "...Las Cortes Constituyentes en uso de sus facultades decretan y sancionan la supuesta Constitución de la Monarquía Española...» y 1869.

9 Kelsen, en Teoría general..., cit. p. 431.

10 Tampoco se puede considerar al Estado como comunidad, pues no existe un derecho de los individuos frente al Monarca. Ver JeLLINECK, Teoría del Estado, Albatros, Buenos Aires, 1970, p. 507. Sólo en la medida en que las relaciones de poder, gobernantes-gobernados, queden sometidas a la ley y convertidas en relaciones juridicas existe el Estado Constitucional. 
Santo Tomás de Aquino, en la Suma Teológica, lo expresa muy claramente cuando escribe.

"Se dice que el Príncipe está exento de la ley en cuanto fuerza coactiva. Porque propiamente hablando nadie se fuerza a sí mismo y toda la fuerza coactiva que tiene la ley la recibe del soberano. Asi, pues, decimos que el soberano está exento de la ley porque nadie puede dictar contra él juicios condenatorios en caso de que obre contra la ley.."11

Consecuencia de que el Rey sea inviolable o no enjuiciable o, dicho con otras palabras, que no pueda ser sometido a control jurisdiccional ni a control político, es que resulta irresponsable en todos los ámbitos, pues si el poder lo recibe de Dios, sólo ante Él responde.

Nuestra Constitución actual, como se ha dicho, mantiene estos atributos de la persona del Rey en cuanto que lo declara inviolable e irresponsable; ello significa que el Rey no responde de los actos realizados, ya sean de carácter exclusivamente personal o de carácter político. Es preciso establecer, sin embargo, las oportunas diferencias entre unos y otros en cuanto a que afecten o no al regular funcionamiento de las instituciones.

2.1. Respecto a los actos de carácter personal, siguiendo al profesor Solozábal, nuestro Estado actual puede aceptar la regulación constitucional sobre que la persona del Rey es inviolable, como una fórmula histórica que simboliza el máximo respeto; que genera una mayor protección, de forma que los actos contra el Monarca son tipificados como delitos de la máxima gravedad. Ahora bien, la inviolabilidad entendida como irresponsabilidad jurídica, sólo cubierta en lo referente a los asuntos patrimoniales del Rey por la responsabilidad asumida por el Jefe de su Casa, "constituye una brecha en el Estado de Derecho que sólo puede ser contrarrestada en un nivel político por un compromiso de ejemplaridad del Jefe del Estado» ${ }^{12}$.

En la formulación actual de la Monarquía, que ha sustituido la potestas por la auctoritas, tal compromiso es un importante pilar en la aceptación popular de la institución.

S. TH., II q. 57 a 1 y l; II, q. 96 a 5 ad. 3.

12 Voz "Rey", en Enciclopedia Jurídica Básica, Civitas, Madrid, 1995, to- 
Pese a esta idea, compartida mayoritariamente por la doctrina, la Constitución arbitra indirectamente dos medidas que podrían subsanar políticamente, en su caso, el comportamiento personal inadecuado de un Rey: en primer lugar la abdicación de la Corona ${ }^{13}$ que pese a estar regulada como acto derivable de la declaración de voluntad del propio Rey, puede ser generado por la crítica o censura política; se trata de una sanción impropia, pero en modo alguno inconstitucional, a un ejercicio incorrecto de las funciones regias ${ }^{14}$. En segundo lugar, la propia reforma agravada de la Constitución que lleve a la abolición de la Monarquia.

2.2. Los actos institucionales o de carácter político en los que el Rey participa, precisan alguien que cubra su irresponsabilidad; éste será el refrendante.

La Monarquía es una institución que de forma sorprendente ha sido capaz de evolucionar y adaptarse a las transformaciones del Estado logrando permanecer y ser útil a través del tiempo. El refrendo es el instrumento que lo ha hecho posible: la práctica parlamentaria inglesa, con su peculiar evolución mantenedora de las instituciones modificando su sentido, crea la ficción de que la irresponsabilidad del Monarca significa que no puede obrar solo, sino mediante la coordinación con un Ministro que asume la responsabilidad. Como dice García Canales, el refrendo es el elemento jurídico que sostiene la forma política de la Monarquía parlamentaria ${ }^{15}$.

13 Instituto diferente a la renuncia, que también puede ser generado por causas similares pero que ahora no contemplamos. La abdicación es el desistimiento realizado después de haber alcanzado la Corona; la renuncia, sin embargo, es el desistimiento del derecho sucesorio o de su mera expectativa, hecho previamente a su actualización o ejercicio; hay que tener en cuenta que el titular de la Corona o de un derecho sucesorio no lo cede, sino que se limita a cesar en su derecho. En A. Torres del Moral, Principios de Derecho Constitucional Español, Servicio de Publicaciones de la Facultad de Derecho de la Universidad Complutense, Madrid, 1992, 3. ${ }^{\circ}$ ed., 2. ${ }^{\circ}$ tomo, p. 13. Igualmente R. LóPEZ VILAS, "La sucesión en la Corona (Comentario al articulo 57 de la Constitución)", en P. LucAs Veroú, La Corona y la Monarquía Parlamentaria, Servicio de Publicaciones de la Facultad de Derecho, Universidad Complutense, Madrid, 1983.

14 Solózabal, J. J., op. cit., p. cit.

15 Voz «Refrendo de los actos del Rey», en Enciclopedia Jurídica Básica, Civitas, Madrid, 1995, tomo IV. En igual sentido, HeRRERo y R. DE Miñón, "Artículo 64 CE. Refrendo de los actos Reales", cit. p. 283. 


\section{IRRESPONSABILIDAD Y REFRENDO EN LA EVOLUCIÓN DE LA MONARQUIAA: DE LA MONARQUÍA ABSOLUTA A LA MONARQUÍA CONSTITUCIONAL; DE LA MONARQUÍA CONSTITUCIONAL A LA MONARQUÍA PARLAMENTARIA}

3.1. Como ya se ha visto, en la Monarquía absoluta de la Edad Moderna el soberano - el Rey, creador del orden jurídico- es inviolable e irresponsable y se encuentra por encima del derecho en el sentido de que está sometido a la vis directiva de la ley pero no a su vis coactiva $^{16}$. Existe la institución del refrendo ${ }^{17}$ en cuanto que alguien pone su firma tras la del Monarca pero tal refrendo tiene inicialmente el sentido de una simple formalidad que autentica o da fe de un acto, cuya decisión depende sólo de la libre voluntad del Rey ${ }^{18}$; a través de esa firma se puede conocer qué secretario del Rey ha preparado la norma o en presencia de quién se ha realizado el acto político e, incluso, la persona que ha de ejecutar lo que el Rey ha ordenado. Posteriormente, cuando el Monarca se ve obligado a delegar numerosas funciones, firma el Secretario en quien delega ${ }^{19}$, que asume responsabilidad exclusivamente ante aquél.

3.2. El paso de las antiguas Monarquías de origen divino a la Monarquia Constitucional o parlamentarismo dualista propia del siglo $\mathrm{XIX}$ y principios del $\mathrm{XX}$, es producto de la evolución en Inglaterra y de

16 «El Rey no recibe su Reino más que de Dios», «El Rey es Emperador en su Reino" o "La voluntad del Rey es ley" son máximas de los legistas franceses que diseñan la teoría de la Monarquía absoluta durante el reinado de Felipe IV (12851314). En este sentido ver A. HAURIOU, Derecho Constitucional e Instituciones políticas, Ariel, Barcelona, 1971.

17 En Ruiz del CASTILlo, op. cit., p. 641. Igualmente L. SANChez Agesta, en EI Sistema Político de la Constitución Española de 1978, Editora Nacional, Madrid, 1978, p. 204.

18 "Signo de mí, Felipe Clemente, protonotario de dicho Serenísimo Señor Rey, y por su autoridad Notario Público en todas sus tierras y señoríos... por mandato de dicho Señor Rey, hice, escribí y cerré», es fórmula empleada tras la contrafirma, en la Provisión del Rey Fernando el Católico, el 14 de abril de 1481, nombrando a su esposa corregente. En Garcia Gallo, A., Manual de Historia del Derecho Español. Antología de Fuentes, tomo II, Artes Gráficas y Ediciones, Madrid, 1959, p. 695. Esta fórmula que se utiliza como ejemplo es anterior al Estado absoluto, pero se mantendrá en sus comienzos de forma muy semejante, a los efectos que perseguimos.

19 "Como Secretario del Rey con ejercicio de decretos y habilitado especialmente para éste, Pedro de Macanaz...", fórmula empleada, tras la contrafirma, en el Decreto de 4 de mayo de 1814, dado en Valencia por Fernando VII. En Garcia Gallo, A., op. cit., p. 1085. 
la revolución en la Europa continental aunque en ambos existió la voluntad de limitar el poder del Monarca ${ }^{20}$. En Inglaterra se hace en un lento y flexible proceso histórico, a través de la costumbre jurídicamente vinculante; proceso que se inicia en la Edad Media sin necesidad de ruptura sino gracias a la permanencia de las instituciones cambiando de sentido. En la Europa Continental se hará en un momento histórico concreto, la Revolución Francesa, mediante la Constitución escrita como instrumento racional de someter a derecho el poder del gobernante para defender los derechos de los gobernados.

Centrados en la Europa continental, la esencia del problema radica en el enfrentamiento entre el principio monárquico y el principio democrático; mientras aquél significa que la soberanía reside en el Rey, fuente de todo poder, el segundo supone que la soberanía reside en el pueblo. Dentro del enfrentamiento de legitimidades - la histórica y la democrática - a lo largo del siglo XIX y primera parte del XX, se va generando el parlamentarismo como sistema de gobierno. Sin entrar en la evolución puntual, vamos a señalar varias etapas en el largo camino durante el que el principio monárquico va perdiendo fuerza en beneficio del principio democrático.

3.2.1. Las Monarquías Restauradas tras la derrota de Napoleón, ya pasados los ardores revolucionarios de la primera hora con un efímera primacia del principio democrático ${ }^{21}$, intentan recuperar sus poderes, otorgando Cartas Constitucionales que, manteniendo la soberanía regia, admiten alguna limitación a sus prerrogativas a través de un Parlamento muy poco representativo. El Rey nombra a sus Ministros que no son responsables políticamente ante el Parlamento, teniendo únicamente responsabilidad penal. Éste es el modelo establecido en España por el Estatuto Real de 1834.

Pese a ello no cabe duda que, desde la práctica parlamentaria, se va iniciándo tímidamente el parlamentarismo dualista que se impondrá a partir de 1837. pp. 252-253.

20 M. García Pelayo, Derecho Constitucional Comparado, CEC, Madrid, 1984,

21 Asi, nuestra Constitución de 1812, en la que la soberania pertenece a la Nación y el Rey y las Cortes son poderes constituidos. En este sentido se expresa el diputado constituyente don Agustín Argüelles: «... El Rey tiene el poder Ejecutivo porque la Nación, a través de la Constitución, lo deposita en sus manos...". 
3.2.2. Parlamentarismo dualista o de doble confianza: la Monarquía Constitucional. El Rey mediante una Constitución pactada comparte la soberanía con la Nación, representada por un Parlamento elegido por sufragio censitario, cada vez más amplio, hasta desembocar en el universal masculino de finales de siglo. Es titular del Poder Ejecutivo y nombra un Gobierno que irá evolucionando hacia un organismo colegiado con un Presidente al frente, $y$ su inicial responsabilidad penal derivará hacia una doble responsabilidad política: ante el Órgano legislativo elegido por sufragio y ante el Rey que lo ha nombrado libremente. Este es el modelo establecido en España en las Constituciones de 1837, 1845 y 1876.

Sin embargo, al menos en los primeros momentos del Estado Constitucional, la inviabilidad de la exigencia parlamentaria de esa responsabilidad política es un hecho demostrado, problema gravísimo que desborda este trabajo22.

Desde el momento en que, a través de la Constitución, se acepta la división de poderes, atribuyendo poderes distintos a órganos diferentes y responsables, el refrendo cambia de sentido convirtiéndose en una limitación formal de la decisión libre del Monarca. Como dice Kelsen, el hecho de que en una Monarquía Constitucional el Rey sea irresponsable ante el Parlamento es un residuo de la Monarquía absoluta; como concesión al principio de división de poderes, los actos de aquél han de estar refrendados por los Ministros de su Gobierno, que responden ante el órgano legislativo ${ }^{23}$.

En resumen, se parte de que el Rey posee un poder efectivo que necesita ser controlado ya que, al ser inviolable no puede exigírsele responsabilidad; mediante el refrendo, que actúa como garantía, se arbitran dos tipos de controles: en primer lugar, carece de validez la libre decisión del Rey sin contrafirma ministerial; en segundo lugar, ese Go-

22 Tratado de forma rigurosa por A. NiETo en Los primeros pasos del Estado Constitucional, cit. p. 473: "El fracaso de la responsabilidad Ministerial es un hecho histórico verificado: nunca llegó a prosperar en sede parlamentaria y careció hasta de regulación legal suficiente... Las consecuencias... fueron gravísimas... en el Estado Constitucional de la Regencia de María Cristina, la Reina Gobernadora era irresponsable y la legitimidad y legalidad del Estado quedaban asegurados únicamente por la responsabilidad de los Ministros... Si luego resultaba que los Ministros de hecho también eran irresponsables, había que aceptar la irresponsabilidad total del Estado: lo que significaba que su exigencia ya no podía llevarse a las Cortes sino a la calle...". Ver igualmente, S. CORONAS GonzÁlEz, "La responsabilidad de los Ministros en la España constitucional", cit.

23 En Teoria General del Derecho y del Estado, cit. pp. 334 y 357. 
bierno que admite el acto del Rey, responde políticamente ante el Parlamento, que puede derrocarle ${ }^{24}$.

Sin embargo y al margen de las construcciones teóricas, en la Monarquía Constitucional de doble confianza la figura del refrendo descansa en una ficción y sólo es relevante en casos puntuales en que se manifiesta la verdadera voluntad Real, puesto que quienes habitualmente ejercen el poder son los Ministros. Como dice A.Nieto: «El mecanismo efectivo era circular y nada tenía que ver con las ficciones constitucionales: el Ministro - o el Consejo de Ministros - adoptaba una decisión que elevaba al Rey para que éste la hiciese suya; y luego el Rey se la devolvía a su autor real para que refrendase la decisión formalmente adoptada por el Monarca» ${ }^{25}$

Por tanto, si bien en unos casos al Rey corresponde la decisión, en otros muchos la comparte con el Gobierno, aceptando su propuesta; siempre con la posibilidad de retirarle su confianza; luego, ya desde el inicio de la institución, el contenido del refrendo varía y en muchos casos se apoya en una ficción jurídica.

Tanto en uno como en otro supuesto, existe un acuerdo de voluntades ${ }^{26}$ y es el refrendante quien responde jurídica y políticamente del acto del Monarca que, sin refrendo, carece de validez.

Conviene recordar las palabras del iuspublicista del pasado siglo, Colmeiro ${ }^{27}$, en este sentido:

"La teoría constitucional exige que el Rey sea inviolable en su persona y en su dignidad; y como este principio pudiera dar ocasión a graves abusos si no tuviere un contrapeso, responden los Minis-

24 Nuestras Constituciones históricas son muy claras en este sentido, estableciendo que "son responsables los Ministros" y que "Todo lo que el Rey mandare o dispusiere en el ejercicio de su autoridad, deberá ser firmado por el Ministro a quien corresponda y ningún funcionario público dará cumplimiento a lo que carezca de este requisito" (Constitución de 1837), o con una expresión más actual: "Ningún mandato del Rey puede llevarse a efecto si no está refrendado por un Ministro, que sólo por este hecho se hace responsable" (Constitución de 1876). Asi, ver los artículos 44 y 61 de la Constitución de 1837; 42 y 64 de la Constitución de 1845; 67 y 87 de la Constitución de 1869, y 49 de la Constitución de 1876.

Sobre esto ver J. Pérez Royo, Curso de Derecho Constitucional, Marcial Pons, Madrid, 1994, p. 445.

${ }_{25}$ Op. cit, p. 201.

26 N. Pérez Serrano, op. cit., p. 732.

27 Op. cit., p. 116. En igual sentido, D. E. AlLeR, Exposición elemental de Derecho Político, Librería de Victoriano Suárez, Madrid, 1875, pp.106-108. 
tros de todos los actos emanados de la Corona, por lo cual es un deber de todo ciudadano rehusar el cumplimiento de cualquiera mandato firmado por el Rey si no viene refrendado por un Ministro. De aquí resulta que si bien la potestad de ejecutar las leyes reside de derecho en el Rey, de hecho está encomendada a los Ministros que aceptan o rehúsan la responsabilidad de su ejercicio, así como el Rey puede destituirlos cuando no merezcan su confianza y nombra a otros con entera libertad, salva siempre la conveniencia del Estado que pone límites según la prudencia, a esta prerrogativa de la Corona."

3.3. A partir de fines del siglo XIX y primeros del XX, en la Europa continental se iniciará lentamente una evolución de esa Monarquia de doble confianza hacia la Monarquía parlamentaria o parlamentarismo monista, que va a suponer el triunfo del principio democrático y la posibilidad de permanencia de la institución.

Se va a evolucionar hacia una concepción novedosa de la institución en la que la soberanía solo pertenece al pueblo, representado por un Parlamento elegido por sufragio universal; el Poder Ejecutivo es ejercido por el Gobierno, votado y mantenido por el Parlamento, cuya única confianza necesita y ante el que es responsable políticamente: los Ministros forman el Gobierno como personas de confianza del Parlamento, de manera que el Rey no puede nombrar sino a aquellos que gocen de tal confianza.

El Rey se convierte en titular de un órgano, la Jefatura del Estado; carece de poderes y es una Magistratura de autoridad. El triunfo de la democracia no admite que tenga poder quien es irresponsable y accede al cargo exclusivamente por herencia; su irresponsabilidad es cubierta por el refrendo del Ministro competente.

En muchos Estados de la Europa continental esta evolución se va a llevar a cabo sin reformar la Constitución, a través de costumbres jurídicamente vinculantes que originan mutaciones constitucionales no reflejadas en el texto escrito; como dice Aragón Reyes, hasta la mitad del siglo XX las Monarquias de la Europa continental conservarán sus Constituciones con una letra de Monarquía constitucional del siglo XIX y con una práctica, que es donde la evolución opera, de Monarquía parlamentaria del siglo $X X^{28}$. Es hacia mitad de nuestro siglo cuando algunos Estados, como Suecia, Dinamarca o Bélgica, han reformado sus 
Constituciones llevando la práctica ya consolidada a la letra de la Norma Fundamental; otros, sin embargo; como Holanda o Noruega ${ }^{29}$ han preferido seguir con la evolución apoyada en las mutaciones constitucionales.

Diferente es el caso de España en que la Monarquía había sido abolida en 1931. Cuando las Cortes Constituyentes de la transición redactaron la Norma Fundamental optaron, en contra del criterio del General Franco cuando nombró sucesor a título de Rey a don Juan Carlos, por una regulación de la institución que respondiese fielmente al parlamentarismo monista, al que han llegado las numerosas Monarquías Europeas por evolución, compatible con el Estado democrático de nuestros días.

Siguiendo al profesor Aragón Reyes ${ }^{30}$ sólo es posible unir Monarquía y democracia cuando aquella es parlamentaria. En este tipo de Monarquía perviven los rasgos irrenunciables de la institución: sucesión hereditaria, ejercicio vitalicio de la Jefatura del Estado e irresponsabilidad regia ${ }^{31}$, trasladando toda decisión al Gobierno que refrenda los actos del Rey; el Estado, a su vez, es democrático porque mantiene los caracteres esenciales de la democracia: soberanía popular, emanación democrática del derecho y responsabilidad de los poderes públicos.

En conclusión, la aceptación por el Estado democrático de la Monarquía, con sus rasgos históricos característicos, exige: en primer

29 El Reino de Noruega reformó su Constitución de 1814 en 1990; sin embargo, tal reforma no modificó ninguno de los artículos que regulan la Corona; pese a ello, la práctica de su Monarquía responde fielmente a la concepción actual de la misma. Ver M. García Canales en "Las Monarquias parlamentarias Europeas", Estudios sobre la Monarquía, UNED, 1996, p. 43.

En dicha Constitución puede leerse que «el poder Ejecutivo reside en el Rey" (art. 3) o que "La persona del Rey es sagrada" (art. 5), o bien que «El Rey tiene potestad para movilizar tropas, declarar hostilidades en defensa del Reino y pactar la paz..." (art. 26); por último, la fórmula del juramento, que establece el artículo 9: "...Prometo y juro que gobernaré el Reino de Noruega de acuerdo con su Constitución y sus Leyes, así me ayude Dios, Todopoderoso y Omnisciente".

30 Ver, en este sentido, Dos estudios sobre la Monarquía parlamentaria en la Constitución Española, Civitas, Madrid, 1990.

31 Como dice Solozábal, el que la transmisión hereditaria y la irresponsabilidad regia sean elementos esenciales de la Monarquía, permite entender determinados institutos de la regulación jurídica de la Corona, como la inhabilitación del Rey; no es un medio extraordinario de exigencia de responsabilidad política, sino una consecuencia lógica de la incapacidad física o mental sobrevenida a una persona que ejerce la Jefatura del Estado de forma vitalicia. Voz «Irresponsabilidad e inviolabilidad del Rey", en Enciclopedia..., cit, tomo III. 
lugar, la imposibilidad de que el Rey tome decisiones políticas propias, limitándose a ejercer competencias tasadas y debidas. En segundo lugar, que todas sus actuaciones, salvo las excepciones previstas constitucionalmente, sean cubiertas por el refrendo del órgano que asume la responsabilidad ${ }^{32}$.

Sea cual sea el camino a través del que se ha llegado a la concepción actual, la Monarquía parlamentaria supone una construcción empíricamente perfecta en que el Rey ha de ser contemplado desde un doble punto de vista: jurídico y político. Jurídicamente, el Rey no tiene poderes efectivos sino competencias tasadas y debidas; es decir, no actúa solo sino a propuesta de otro órgano, sin posibilidad de veto. Desde el punto de vista político, su situación al margen de la política diaria le dota de una posición privilegiada para uanimar, advertir y ser consultado", no debido al poder, del que carece, sino a la autoridad que puede lograr, aportando al Estado democrático estabilidad, unidad y permanencia y posibilitando, como ningún otro órgano, la integración territorial, cultural, social y política ${ }^{33}$. Estos rasgos esenciales, apoyados en la auctoritas, han posibilitado la permanencia de la institución; son señalados por $O$. Alzaga de forma muy expresiva:

«Capacidad para representar al conjunto de la Nación, y no sólo a las generaciones actuales; su condición natural para encarnar el pasado histórico de su pueblo, su idoneidad para representar los valores permanentes del Estado...; su independencia natural frente a los partidos y a las pugnas políticas...con la virtud de la neutralidad que esa independencia conlleva y su carácter de garantía de continuidad, sin interregnos ni sobresaltos., ${ }^{34}$

Desde esta concepción de la Monarquía se va a analizar la institución del refrendo en la Constitución Española actual.

32 En este sentido, J J. Solozábal Echavarría, voz "Irresponsabilidad e inviolabilidad...", en Enciclopedia Jurídica..., cit.

33 Ver M. Aragón Reyes, "La Monarquía parlamentaria», en A. Predieri y E. Garcia de Enterria, La Constitución Española de 1978, Civitas, Madrid, 1980. Voz "Corona", Enciclopedia..., cit, tomo II.

34 En Derecho Político Español, Ed.Ramón Areces, Madrid, 1996, p. 420. 


\section{EL REFRENDO EN LA CONSTITUCIÓN ESPAÑOLA DE 1978}

\subsection{Concepto}

Artículo 56,3 CE:

"La persona del Rey es inviolable y no está sujeta a responsabilidad. Sus actos estarán siempre refrendados en la forma establecida en el artículo 64, careciendo de validez sin dicho refrendo, salvo lo dispuesto en el artículo 65.2."

\section{Artículo $64 \mathrm{CE}$ :}

"Los actos del Rey serán refrendados por el Presidente del Gobierno $y$, en su caso, por los Ministros competentes. La propuesta y nombramiento del Presidente del Gobierno, y la disolución prevista en el artículo 99, serán refrendados por el Presidente del Congreso."

\section{Artículo 65,2 CE:}

"El Rey nombra y releva libremente a los miembros civiles y militares de su Casa.»

El refrendo, instituto esencial en la aceptación de la Monarquía por el Estado democrático, es el mecanismo constitucional por el que el órgano competente asume la responsabilidad derivada de la actuación del Rey, bien mediante la firma en un documento, bien mediante la presencia física en un acto institucional.

De lo dicho pueden extraerse las siguientes consecuencias, que se irán desarrollando a lo largo del trabajo.

En primer lugar, si en nuestra historia constitucional el acto del refrendo de los actos jurídico constitucionales partía de la presencia de dos voluntades coordinadas, que manifiestaban una decisión política; en la Monarquía parlamentaria establecida por la Constitución actual existe una única voluntad: bien la del refrendante, bien la de otro Órgano del Estado ajeno a aquél; sólo en supuestos muy concretos y tasados, la del Monarca.

La firma del Rey no manifiesta, ordinariamente, una decisión política sino la perfeccción de un acto como acto de Estado, de cuya unidad y permanencia es símbolo. Pese a lo dicho, ambas firmas, la del Rey y la del refrendante, son imprescindibles para la existencia y validez del acto. 
En segundo lugar, el refrendo supone la traslación de responsabilidad del Rey al refrendante como técnica constitucional que salva el atributo de inviolable que se predica de la persona del Monarca. Esa responsabilidad asumida por el refrendante tiene, según los casos, distinto contenido o extensión.

Por ultimo, el refrendo presupone el conocimiento por parte del Monarca de los asuntos de Estado, de los que estará convenientemente informado y en los que, a través de su auctoritas, podrá "animar y advertir....135.

\subsection{Sujetos que intervienen}

En el ejercicio de las funciones que la Constitución atribuye al Jefe del Estado, son necesarias dos presencias: la del Rey y la del refrendante.

- El Rey que ejerce una competencia, obligatoria pero imprescindible, para posibilitar el funcionamiento regular de las instituciones. Con su actuación que ordinariamente no incluye decisión alguna, manifiesta la suprema voluntad del Estado.

- El refrendante, que asume la responsabilidad del acto del Monarca, según la forma expresamente fijada en el artículo 64 de la Constitución.

La Constitución no se limita a señalar la necesidad de refrendo de los actos del Monarca dejando a regulaciones de desarrollo o a la propia práctica constitucional el establecimiento de los órganos competentes en cada caso; por el contrario, y como ha interpretado el Tribunal Constitucional ${ }^{36}$, el artículo 64 dirige un mandato inequívoco y no delegable - como establecido por la Norma suprema del Ordenamiento Jurídico ${ }^{37}$ - al Presidente del Gobierno o, en su caso, a un Mi-

35 En este sentido ver De Esteban, J., y González-Trevijano, P. J., en Curso de Derecho Constitucional Español, tomo III, cit. p. 80.

36 STC 5/1987, de 27 de enero. FJ 2; doctrina reiterada en STC 8/87, de 29 de enero.

37 El artículo 20 de la Ley 50/1997, de 27 de noviembre, del Gobierno, manifiesta que no son en ningún caso delegables las competencias atribuidas directamente por la Constitución. 
nistro competente en razón de la materia, con tres excepciones expresas: la propuesta de candidato a Presidente del Gobierno; el nombramiento del Presidente del Gobierno y la disolución de las Cámaras parlamentarias prevista en el artículo 99 de la Constitución.

De esta regulación pueden desprenderse las siguientes consideraciones, tanto respecto al sujeto refrendante como al contenido del refrendo.

En primer lugar, la Constitución y la Ley 50/1997, de 27 de noviembre - del Gobierno- que la desarrolla en este punto, diseñan un refrendo individual, bien del Presidente del Gobierno ${ }^{38}$ bien de un $\mathrm{Mi}$ nistro ${ }^{39}$; no contempla el refrendo colectivo del Consejo de Ministros, como manifestación de solidaridad con la decisión tomada, ni el de otros miembros del Gobierno, jerárquicamente subordinados a los Ministros, que pudiera establecer una ley a tenor del artículo 98,1 CE; situación inexistente en la actualidad ya que, según el artículo 1 de la Ley 50/1997, citada, el Gobierno se compone, exclusivamente, del Presidente, del Vicepresidente o Vicepresidentes, en su caso, y de los Ministros.

En segundo lugar, la Constitución no autoriza a refrendar a cualquier Ministro del Gobierno, sino al competente; es decir, aquél a cuyo Ministerio corresponda la esfera específica de actuación ${ }^{40}$. En este sentido se expresa el artículo 4,1,d de la Ley 50/1997, de 27 de noviembre, citado, "Refrendar, en su caso, los actos del Rey en materia de su competencian; lo dicho anteriormente obliga a rechazar el posible refrendo de un Ministro sin Cartera.

Esta regulación, por otro lado, es acorde con nuestra tradición constitucional; todos los Textos, salvo el de 1876 que omite tal puntualización, se acogen al criterio competencial en razón de la materia. En la Restauración, pese a la ausencia de norma, se respetó tal práctica constitucional, ya consolidada:

- Constitución de 1812 (art. 225): «Todas las órdenes del Rey deberán ir firmadas por el Secretario del Despacho del ramo o que el asunto corresponda".

38 Art. 2.h - del Presidente del Gobierno- de la Ley 50/1997, de 27 de noviembre: "Refrendar, en su caso, los actos dél Rey...".

39 Art. 4.d - de los Ministros - de la Ley 50/1997, de 27 de noviembre: «Refrendar, en su caso, los actos del Rey...n.

40 Art. 4.1 de la Ley 50/1997, de 27 de noviembre. 
- Constituciones de 1837 (art. 61); 1845 (art.) y 1869 (art. 87): "Todo lo que el Rey mandare o dispusiere en el ejercicio de su autoridad deberá ser firmado por el Ministro a quien corresponda... ${ }^{41}$.

Existen, sin embargo, algunas decisiones de política competencial interministerial que parecen escapar a la regla general señalada anteriormente. El artículo 24 de la Ley de Régimen Jurídico de la Administración del Estado, de 26 de julio de 1957, parcialmente vigente hasta la aprobación de la Ley del Gobierno, entendía que si afectare a varios Ministerios, "el Decreto se dictará a propuesta de los Ministros interesados y será refrendado por el Presidente del Gobierno o el Ministro de la Presidencia " ${ }^{42}$. La señalada Ley del Gobierno no contempla este caso de forma explícita; ha de entenderse aplicable la regla general de refrendo individual, tradicional en nuestro sistema político; es decir, el Real Decreto se dictará a propuesta de los Ministros interesados y será refrendado por el Presidente del Gobierno cuando corresponda a normativa básica del Estado y del Ministro de la Presidencia - responsable de la coordinación interministerial ${ }^{43}$ - cuando se catalogue como normativa competencial, aunque afecte a varios Departamentos. La práctica política posterior a la aprobación de la Ley del Gobierno, se mueve en el sentido señalado.

En tercer lugar, la interpretación del artículo 64 de la Constitución no ha sido pacífica sino que ha suscitado polémica, decidida por el Tribunal Constitucional en la Sentencia 5/1987, de 27 de enero con motivo del nombramiento del Lehendakari Vasco, refrendado por el Presidente del Gobierno ${ }^{44}$. Los argumentos expuestos fueron los siguientes.

41 La Constitución de 1876, sin embargo, no especifica; dice así en su artículo 49: "Ningún mandato del Rey puede llevarse a efecto si no está refrendado por un Ministro, que por sólo este hecho se hace responsable".

42 La Ley de Organización y funcionamiento de la Administración General del Estado 6/1997, de 14 de abril, mantuvo en vigor, en tanto no se aprobase la Ley del Gobierno, los arts. 2, 4, 5, 8, 10, 11, 12, 13, 14-2; 22,1 y $2 ; 23,2 ; 24,25$ y 32,1 de la LRJAE de 1957.

La Ley 50/1997, de 27 de noviembre, del Gobierno, deroga los artículos de la LRJAE que, según se ha señalado, continuaban vigentes.

43 Artículo 1.c del RD 765/1996, de 7 de mayo.

44 Este supuesto originó un conflicto de competencia positivo ante el Tribunal Constitucional, presentado por el Gobierno Vasco frente al Gobierno del Estado por entender que el Real Decreto 771/1984, de 16 de abril, por el que se nombró Presidente del Gobierno Vasco a don Carlos Garaicoetchea Urriza, debió ser refrendado por el Presidente del Parlamento Vasco y no por el Presidente del Go- 
Una primera interpretación ${ }^{45}$, parte de la imputabilidad de la responsabilidad, de la que ha de derivar la competencia para refrendar. En consecuencia se hace la siguiente lectura de los artículos señalados.

- Es preciso poner en relación los dos apartados del art. 64 para llegar a una interpretación coherente de la Constitución.

- El art. 64.2 CE dispone que «de los actos del Rey serán responsables las personas que los refrenden". Por tanto, la esencia del refrendo es la asunción de responsabilidad por el refrendante; de ello deriva la necesidad de identificar al órgano responsable del acto para determinar quién es competente para refrendar.

- Si bien el art. 64.1 determina que «Los actos del Rey serán refrendados por el Presidente del Gobierno y, en su caso, por los Ministros competentes", ello debe entenderse siempre y cuando el acto que refrenden encaje en su ámbito competencial.

- En consecuencia, el mandato del art. 64.1 ha de considerarse una cláusula general de la que se deben excluir aquellos actos en los que tales refrendantes no han fijado su contenido, luego no pueden responder del mismo: en concreto las Leyes, aprobadas por el Parlamento, y el nombramiento de Presidente de una Comunidad Autónoma, elegido por su Asamblea.

Una segunda interpretación, avalada por el Tribunal Constitucional46, considera que en nuestra Constitución la responsabilidad es efecto de la competencia para refrendar. $y$, en consecuencia, la lectura del precepto ha de ser la siguiente.

- Los actos del Rey deben ser siempre refrendados, con la salvedad prevista en el propio art. 56.3.

bierno del Estado, "a quien no corresponde ninguna responsabilidad en la designación del Lehendakari Vasco». Fue decidido por la Sentencia 5/1987, de 27 de enero, citada numerosas veces; doctrina reiterada en la STC 8/1997, de 29 de enero, con motivo del nombramiento del Lehendakari José Antonio Ardanza Garro por RD 82/1985, de 25 de enero.

45 Mantenida por las representaciones del Gobierno y del Parlamento Vasco en STC cit.

46 Criterio del Abogado del Estado, respaldado por la decisión del Tribunal Constitucional, en la STC cit. 
- En ausencia de refrendo, carecen de validez.

- El mandato derivado del artículo 56.3 impide admitir otras formas de refrendo que no sean las previstas en el art. 64.

- La autoridad refrendante en cada caso asume la responsabilidad del acto del Rey. Tal responsabilidad tiene un contenido distinto, de forma que el refrendante bien responde de la decisión y de la corrección constitucional de la actuación del Monarca; bien sólo de ésta última.

Efectivamente, y en ello se apoya el Tribunal, éste ha sido el sentido del refrendo en nuestra tradición constitucional, consecuencia de la evolución de la Monarquía. Mientras que el Rey es cabeza del Poder Ejecutivo y comparte el Poder Legislativo, a través de la iniciativa y la posibilidad de veto ${ }^{47}$, se puede entender que todos los actos del Estado dependen de la voluntad del Rey o, al menos, del acuerdo de voluntades con su Gobierno ya que, como se ha dicho, desde el inicio del régimen constitucional es este acuerdo de voluntades, con el acento puesto en una $u$ otra de las partes, el que determina el contenido de los actos.

Desde el momento en que se inicia el tránsito hacia la parlamentarización de la Monarquía en la que el Rey no decide y asume exclusivamente la función de Jefe del Estado, símbolo de su unidad y permanencia, todos los actos que lleva a cabo por mandato constitucional -en el ámbito de cualquier Poder- son imprescindibles pues culminan la voluntad del Estado, pero han de estar refrendados ya que el Monarca es irresponsable. Ahora bien, si en el ámbito del Poder Ejecutivo son decididos por quien refrenda, no sucede así en el de los demás Poderes en los que ya no participa de forma decisoria el Ejecutivo; el refrendante, pues, sólo puede asumir la legitimidad constitucional del acto del Monarca porque sólo cubre su irresponsabilidad.

En cuarto lugar ${ }^{48}$, y en consecuencia con lo dicho anteriormente, el refrendo acredita siempre que el Monarca ha actuado conforme a las prescripciones constitucionales y el refrendante asume la responsabilidad por este juicio de legalidad; sólo cuando el acto refrendado de-

47 Solamente en la Constitución de 1869, el Rey carece de veto; sí mantiene la iniciativa legislativa compartida con las Cortes.

48 Ver M. Herrero y R. DE Miñón, "Art.64. Refrendo de los actos Reales», cit., pp. 302-303. 
penda de la decisión del Poder Ejecutivo, el refrendante puede responsabilizarse también de la oportunidad política de la decisión, asumiendo tal responsabilidad.

Por último, las tres excepciones contempladas en el artículo 64 $C E$, descansan en la consideración de que son situaciones en que no existe un Presidente del Gobierno investido con la confianza parlamentaria sino, por el contrario, un Gobierno en funciones; entre el posible refrendo por el Presidente de éste o por el de la Cámara, el constituyente ha optado por esta regulación ${ }^{49}$, y parece que la decisión se apoya en sólidas razones.

La Constitución admite, obviamente, la gestión ordinaria de un Gobierno en funciones $y$, en consecuencia, el refrendo de un Ministro dimisionario en aquellos actos en que se ejercen competencias relativas al despacho ordinario de los asuntos públicos tendentes a mantener el funcionamiento del Estado. Ello supone, a sensu contrario, el rechazo de que adopte cualquier decisión política esencial, con el necesario refrendo de la misma ${ }^{50}$, porque no debe ser responsable de tal decisión un Gobierno a quien el Congreso de los Diputados no puede sancionar políticamente mediante una moción de censura.

Aunque las situaciones contempladas en el artículo 64 de la Constitución - propuesta y nombramiento de Presidente del Gobierno y disolución de las Cámaras, con la convocatoria de nuevas elecciones, por no haber obtenido ningún candidato la confianza del Congreso en el plazo de dos meses a partir de la primera votación de investidura - no son decisiones de un Gobierno dimisionario sino consecuencia de su situación política, son supuestos esenciales; en consecuencia, el rechazo de un refrendo gubernamental se apoya en la misma filosofía. Como dice Cáceres Crosa: "...los actos realizados bajo semejante refrendo, del que no se deriva responsabilidad Ministerial, aparecerán como decisiones puramente personales del Jefe del Estado y en los regímenes en que el órgano supremo es irresponsable nadie habrá que responda de esta actividad notoriamente arbitraria....n ${ }^{51}$.

49 Sentencia citada del Tribunal Constitucional, FJ 3.

50 Art. 21.3 de la Ley 50/1997: "El Gobierno en funciones... limitará su gestión al despacho ordinario de los asuntos públicos, absteniéndose de adoptar, salvo casos de urgencia debidamente acreditados o por razones de interés general cuya acreditación expresa así lo justifique, cualesquiera otras medidas".

51 Citado por M. HeRrero Y R. DE Miñón en p. 292 de la obra señalada numerosas veces. 


\subsection{Objeto y modalidades del refrendo}

En los actos del Rey que precisan refrendo hay que distinguir distintos tipos $y$, en consecuencia, diferentes modalidades en el ejercicio del mismo. Como consecuencia de la propia evolución del sistema parlamentario, en unos casos la responsabilidad asumida por el refrendante es exclusivamente formal; en otros alcanza también al contenido del acto.

\subsubsection{Actos jurídico-constitucionales}

La irresponsabilidad del Monarca en un Estado democrático, consecuencia de su cualidad de inviolable, ha de ser cubierta por la responsabilidad de los poderes públicos, manifestada en el refrendo obligatorio de todos aquellos actos que contribuyen directamente a formar la voluntad del Estado. La manifestación de esa voluntad del Estado con la firmeza, solemnidad y generalidad que debe tener, exige la intervención del Jefe del Estado ${ }^{52}$ y un refrendo expreso y escrito de quien asume la responsabilidad del acto; por tanto la firma del Rey y la contrafirma del refrendante han de ser simultáneas y plasmadas en un documento, como requisitos imprescindibles para la eficacia del acto.

Sin embargo, atendiendo a la voluntad que ha decidido tal acto, se pueden diferenciar distintos supuestos ${ }^{53}$.

A) Aquél en que el refrendante ha decidido el contenido del acto refrendado, siendo a él imputable la responsabilidad del mismo, de forma que el Rey se limita a firmar algo en que su voluntad no ha intervenido en ningún momento; dicho esto, no se puede olvidar cómo la esencial auctoritas en que ha de apoyarse el Monarca parlamentario, da plena vida al clásico derecho a "animar, advertir y ser informado"en todos los asuntos del Estado ${ }^{54}$.

52 J. J. Solozábal EchavarRía, voz "Irresponsabilidad e inviolabilidad del Rey", Enciclopedia Jurídica Civitas, tomo III.

53 Así lo hace la parte demandante en la STC 8/ 87, cit., Antecedentes. En la doctrina es analizado por L. LÓPEz GuerRa en "Las funciones del Rey y la institución del refrendo", Estudios sobre la Monarquia, cit.

54 En contra de la doctrina mayoritaria, M. HeRrero Y R. DE Miñon defiende un "derecho de examen previo" del Monarca antes de firmar, no como juicio de oportunidad política, sino como garantía de la observancia constitucional, como esen- 
Como supuesto tipo, el establecido en el artículo 62.e de la Constitución: «nombrar y separar a los miembros del Gobierno a propuesta de su Presidente"; igualmente, las siguientes competencias señaladas en dicho artículo 62: la convocatoria y disolución de las Cámaras y la convocatoria de elecciones; la convocatoria de referéndum, en su caso; la expedición de los Decretos acordados en Consejo de Ministros y la concesión de empleos civiles y militares ${ }^{55}$.

B) Enmarcado en el normal funcionamiento de los poderes del Estado, la Constitución contempla un único supuesto en el que el contenido del acto corresponde al Rey y el refrendante contrafirma una decisión ajena; me refiero a la propuesta de candidato a Presidente del Gobierno que hace el Rey tras las consultas con los líderes parlamentarios; propuesta que comunica al Presidente del Congreso quien, en este caso, refrenda la decisión regia. Es en este acto político donde el Monarca puede tener algún margen de discrecionalidad; bien es cierto que absolutamente mediatizado por los resultados electorales, ya que su prudencia política le llevará a proponer a quien le conste que va a lograr la confianza de la Cámara; ahora bien, cuando no existan mayorías claras sí puede el Rey intentar acercar posiciones, limar desencuentros, lograr consensos, propiciar, en suma, una buena opción política, a través de sus conversaciones con los representantes políticos; de ahí a presentar "un candidato propio" hay un abismo56: el que separa a don Alfonso XIII de don Juan Carlos 157.

En este apartado puede incluirse, aunque con significado distinto al señalado anteriormente, la clásica competencia Regia establecida en el artículo 62.f "Reconocer honores y distinciones"; es decir, la concesión de títulos nobiliarios decididos por el Monarca y aceptados por el Gobierno. Igualmente, algunas decisiones de su vida privada, con gran trascendencia pública: la abdicación, a través de Ley Orgánica (art. 57.5 CE); la prohibición expresa de matrimonio, respecto de alguno de sus posibles sucesores, también mediante Ley Orgánica (art. 57.4 y $5 \mathrm{CE}$ ); y el nombramiento testamentario de tutor para el Rey menor de edad (art. $60 \mathrm{CE}$ ).

cial control interorgánico. En "Artículo 64. Refrendo de los actos Reales", cit. pp. 297-300.

55 Artículo 62, b, c, e, f, i de la Constitución.

56 A. TORRes del Moral, en op. cit., p. 38.

57 Ver M. Gafcla Canales, voz "Refrendo de los actos del rey", Enciclopedia Jurídica Civitas, tomo IV. 
C) Por último, aquellos actos jurídico-constitucionales cuyo contenido no es decidido ni por el Rey ni por el refrendante: así, la sanción de las leyes aprobadas por el Parlamento (artículo 62 a CE); el nombramiento de Magistrados del Tribunal Constitucional, salvo los dos propuestos por el Gobierno (artículo $59.1 \mathrm{CE}$ ) y el nombramiento de Presidente de una Comunidad Autónoma (artículo 152.1.c. CE): con este acto único en el ámbito competencial de las Comunidades Autónomas, se subraya el sentido integrador de la Corona; como dice el TC. «se ha querido hacer visible el nexo por medio del cual la organización institucional de las C A se vincula al Estado, de cuya unidad y permanencia, el artículo 56 de la Constitución define al Rey como símbolo"

Existen, pues, supuestos en el que el refrendante asume la responsabilidad de los actos del Monarca sin haber intervenido en la decisión que los origina; en ellos, como se ha visto, el refrendante responde sólo de "la legitimidad constitucional del acto del Rey»; es decir, responde quien refrenda y responde de la adecuación y corrección de los actos Regios. El refrendo por el Presidente del Gobierno certifica la legitimidad de tal acto, sin entrar en la autoría de la decisión política. Como ha dicho el TC, la evolución sufrida por el poder Ejecutivo en el sistema parlamentario, en que la voluntad Real dejó de determinar el contenido de los actos del Monarca, no se podía producir en aquellos actos del Rey «incardinados» en la esfera de otros poderes.

\subsubsection{Actos políticos con manifestaciones públicas}

En la vida política ordinaria se realizan numerosos actos no recogidos de forma expresa en el texto constitucional, que se han ido consolidando a través de la práctica política, en los que sin duda alguna el Rey ejerce sus funciones de símbolo, moderador y representante del Estado; son actuaciones que afectan al regular funcionamiento de las instituciones y en las que, igualmente, ha de estar refrendado.

En ellos existe un refrendo expreso a través de la presencia física del refrendante en el acto público en que interviene el Monarca y en el que se dirige a diferentes instituciones del propio Estado o de Estados extranjeros, situaciones en que es acompañado por el Presidente del Gobierno o el Ministro competente quienes, lógicamente, han de conocer lo que el Rey va a decir, dada su trascendencia política y su impacto en la opinión pública. Efectivamente, entre las misiones de la Ca- 
sa del Rey, establecidas en el RD 434/1988, de 6 de mayo, se contemplan las relaciones del Rey con los organismos oficiales, entidades $y$ particulares, que tienen relevancia pública y afectan directamente a las funciones simbólicas y representativas que corresponden al Rey como Jefe del Estado ${ }^{58}$.

Pese a lo dicho, conviene matizar más: ¿tiene el Rey un derecho de mensaje como lo tiene un Jefe de Estado de una República parlamentaria, a través del que puede expresar su propio criterio político? En una Monarquía parlamentaria, según hemos visto, no existe tal posibilidad sino que, como dicen P. Tenorio y M. Gonzalo ${ }^{59}$, los discursos regios deben contar con el consentimiento y refrendo del Gobierno; en consecuencia, habrán de ser sometidos al criterio de la Presidencia. Como apuntan los citados autores, no se trata de una cortesía sino de un deber jurídico y así lo entiende el Monarca que, en casos de discrepancia, ha aceptado el criterio del Ejecutivo.

En la práctica de los discursos, el Monarca no asume el programa político del Gobierno sino que adopta una postura neutral, eludiendo siempre un protagonismo político directo; en este sentido, afronta problemas actuales recordando los principios esenciales que inspiran nuestra Constitución y manifestando una total adhesión a los mismos ${ }^{60}$.

Conviene, sin embargo, señalar algunos casos de mensajes regios a las instituciones en los que no existe un Gobierno investido de la confianza parlamentaria sino, por el contrario, un Gobierno en funciones; entre ellos destaca, por ser práctica política consolidada, el mensaje dirigido a las Cortes Generales en la solemne sesión de apertura de cada Legislatura61.

Herrero de Miñón considera que tal mensaje, que no es el tradicional discurso de la Corona ni expresión de ninguna acción partidista sino, en palabras del propio Monarca «impulsora de una acción para todos", es una acción típicamente arbitral que pese al principio general del artículo 64, la fuerza normativa de los hechos que la costumbre

58 Art. 2 de la citada norma.

59 Obra citada, p. 105. M. Herrero y R. DE Miñón mantiene una opinión contraria en "Artículo 64...", cit. pp. 59-62.

60 Gonzalo Gonzalez, M., y Tenorio Sánchez, P., op. cit., p. 117.

61 El artículo 5 del Reglamento del Congreso de los Diputados establece que "Dentro de los quince días siguientes a la celebración de la sesión constitutiva tendrá lugar la solemne sesión de apertura de la Legislatuta». 
expresa, ha configurado como exenta de refrendo62. A la contra, se pueden alegar los siguientes extremos:

- La Constitución exige el refrendo de todos los actos del Rey por las personas designadas en el propio Texto, salvo los supuestos expresamente excluidos; sin aquél, carecen de validez.

- Una actuación concreta del Monarca puede consolidarse a través de la práctica, pero no en contra de lo establecido en la Constitución.

- El Gobierno en funciones facilitará el normal desarrollo del proceso de formación del nuevo Gobierno y el traspaso de poderes al mismo y limitará su gestión al despacho ordinario de los asuntos públicos ${ }^{63} ; y$, en consecuencia, refrendará los actos del Rey que se derivan de la vida ordinaria del Estado.

- Si se ha consolidado la práctica política de que el Monarca presida la sesión de apertura de la Legislatura y dirija un Mensaje a las Cámaras, tal acto será refrendado por el Presidente del Gobierno dimisionario que responderá de la corrección constitucional del mismo y no de su contenido puesto que no se encuentra en situación para ello. De todas formas parece un supuesto alejado de la realidad ya que ni al Monarca parlamentario le corresponde asumir un protagonismo político diseñando un programa de gobierno o apoyando alguno de los existentes, ni nunca lo ha hecho, manteniendo un exquisito respeto a la Constitución.

En conclusión, no existen actos regios carentes de refrendo salvo los expresamente diseñados por la Constitución; $y$ han de estar refrendados por quienes designa la Norma.

En el supuesto contemplado, y en otros similares, si bien no existe Gobierno capaz de asumir una responsabilidad política derivada del contenido de lo manifestado por el Rey, dada la práctica seguida en los discursos regios - que se comunica al Ejecutivo a través de la Casa$y$ en coherencia con la misma, el refrendo de tales mensajes puede

62 M. Herrero y R. de Miñón, en "Artículo 64...", cit. pp. 59-62.

63 Artículo 21.3 de la Ley del Gobierno. 
considerarse asunto propio de un Gobierno en funciones, en cuanto que mantienen el regular funcionamiento de las instituciones; tal refrendo asume exclusivamente la legitimidad y corrección constitucional del acto Regio.

4.3.3. Por último, es preciso contemplar aquellos actos en los que interviene el Monarca en que no existe una presencia física ni, por supuesto, una contrafirma; quizás el más emblemático sea el Discurso que dirige el Rey a todos los Españoles con motivo de la Navidad; no. cabe duda de sus connotaciones políticas.

En estos casos puede hablarse de un refrendo tácito o presunto, muy flexible, que cubre adecuadamente toda actuación del Rey, en cuanto que no exige la coincidencia física ni temporal de refrendante $y$ refrendado ${ }^{64}$ sino que se presume que lo manifestado por el Monarca es asumido por el Gobierno, si no se opone públicamente a ello. Como dice García Canales ${ }^{65}$, «cualquier acto de voluntad o de opinión, de trascendencia política, atribuible a la Corona, se entiende refrendado por el órgano de más próxima competencia»; en el ejemplo señalado, el Presidente del Gobierno.

Ahora bien, si el Rey hace una manifestación opuesta a la política del Gobierno -impensable en una Monarquía parlamentaria- el Gobierno puede negarse a refrendarla, lo que generaría un doble efecto.

- Que el acto del Rey carezca de validez, según establece el artículo 62 de la Constitución.

- Que se abra un peligroso conflicto constitucional entre la Corona y el Gobierno, sostenido por la mayoría de la representación nacional. Ello podría dar lugar a la dimisión del Gobierno si en el debate que se abra se encuentra desasistido por la opinión pública, pese a su fuerza parlamentaria, frente a la auctoritas de la Corona; o, por el contrario, a un desprestigio irreversible de la Jefatura del Estado.

64 En este sentido, ver M. Herrero y R. DE MiÑón, "Artículo 64. Refrendo...", cit. p. 306.

65 Voz "Refrendo de los actos del Rey», en Enciclopedia Jurídica..., ya citada. 


\subsection{Excepciones}

El artículo 65,2 C exceptúa de la garantía del refrendo aquellos actos realizados por el Rey que no contribuyen directamente a la formación de la voluntad estatal: el nombramiento y relevo de los miembros civiles y militares de su Casa, que el Rey decide libremente.

Pese a ello, el Rey, desde el comienza de su Reinado, ha querido someter tales nombramientos - libres - al requisito del refrendo; con ello indica, en primer lugar, el acuerdo del Gobierno con el nombramiento efectuado; en segundo lugar, algo que la Familia Real ha puesto siempre de manifiesto: la inexistencia de Camarillas palaciegas que formen un gobierno paralelo al legítimo Gobierno de la Nación, práctica muy habitual en la Monarquía Constitucional Española del siglo XIX66. La Casa del Rey, en la Monarquía de Don Juan Carlos, es exclusivamente el aparato burocrático al servicio de la Corona, que le aporta los medios personales y materiales para cumplir con independencia sus funciones ${ }^{67}$.

Esta práctica, iniciada voluntariamente por el Rey, ha sido respaldada por una parte de la doctrina, entendiendo que el nombramiento y relevo de los miembros civiles y militares de la Casa, tienen enorme importancia en el marco del funcionamiento de las instituciones $^{68}$. Los acontecimientos del 23 de febrero de 1981, en que se encontró implicado un General que había pertenecido a la Casa del Príncipe de España, dio la razón al criterio doctrinal apuntado y valoró la práctica iniciada por SM; práctica que se puede considerar consolidada, produciendo una mutación constitucional.

66 Sobre todo en los reinados de Isabel II y Alfonso XIII.

67 Ver MEnÉndez ReXACH, A., La Jefatura del Estado en el Derecho Público español, INAP, 1979, p. 156.

El artículo 2 del RD 434/1988, de 6 de mayo, que establece la ordenación general y completa de la Casa de SM el Rey, determina dos tipos de misiones de la misma.

a) Los servicios de infraestructura material y personal que indirectamente posibilitan el ejercicio de las funciones que competen a la Jefatura del Estado y que afectan al protocolo, seguridad y honores, así como a la organización y funcionamiento del régimen interior de la residencia de la Familia Real.

b) Las relaciones del Rey con los organismos oficiales, entidades y particulares, que tienen relevancia pública y afectan directamente a las funciones simbólicas y representativas que corresponden al Rey como Jefe del Estado.

Como dice BAssols COMA, mientras que las primeras sólo tienen trascendencia interna, las segundas pueden poner en marcha mecanismos constitucionales. Op. cit., p. 172.

68 Así, Torres del Moral, op. cit., p. 42. 
En resumen: el Rey, por prudencia política, ha extendido el refrendo a aquellos actos no debidos y decididos libremente, con plenitud de poder decisorio ${ }^{69}$, por imperativo constitucional, generando una mutación constitucional.

Ahora bien, ha de quedar claro que son decisiones libres del Monarca, que comunica al Consejo de Ministros, y no decisiones del Gobierno, como dice la prensa una y otra vez, confundiendo los conceptos, ante la existencia de refrendo voluntario.

\subsection{Efectos del refrendo}

El artículo 56,3 de la Constitución establece expresamente to siguiente.

A) Están desprovisto de validez los actos del Jefe del Estado carentes de refrendo; ello significa que son imprescindibles las dos presencias, la del Rey y la del refrendante, para dotar de validez al acto como acto de Estado.

El refrendo puede hacerse de forma expresa, bien por escrito o mediante la presencia física del refrendante junto a la del Monarca; o de forma tácita, si no existe inmediata oposición del responsable.

En los actos jurídico constitucionales el Rey no puede negarse a firmar, es un acto debido; pero sin su firma el Estado dejaría de funcionar.

B) De forma automática se produce la transferencia de responsabilidad al refrendante. Tal responsabilidad supone siempre el asumir la corrección constitucional del acto realizado por el Monarca; en las ocasiones en que la decisión corresponde al Poder Ejecutivo, supone asumir la legalidad del acto refrendado y su oportunidad política.

C) En los actos jurídico constitucionales que exigen la firma del Rey y un refrendo expreso y escrito que se manifiesta en la contrafirma del refrendante, hay que distinguir distintos supuestos de carencia de los requisitos señalados:

M. Aragón Reves, voz «Rey», en Enciclopedia jurídica básica, citada. 
En primer lugar, la falta de firma Regia; ello supone la inexistencia del acto por ausencia del requisito constitucional que perfecciona el acto $y$ que finaliza el proceso de decisión con la firmeza, solemnidad y generalidad necesaria.

En segundo lugar, la inexistencia de refrendo o el ser prestado por persona inadecuada supone la nulidad absoluta del acto ya que carece del requisito constitucional esencial e imprescindible de la Monarquía Parlamentaria: el cubrir la irresponsabilidad del Jefe del Estado por la persona a quien la Constitución, de forma expresa, atribuye tal competencia.

\section{RECAPITULACIÓN}

La evolución sufrida por la Monarquía ha supuesto una variación paralela en el significado y contenido del refrendo de los actos del Rey. De acuerdo con el análisis realizado en estas páginas, se pueden extraer las siguientes conclusiones, a modo de recapitulación.

A) En la Monarquía absoluta existe la institución del refrendo en cuanto a que alguien pone su firma tras la del Monarca, pero tal refrendo tiene inicialmente el sentido de una simple formalidad que autentifica o da fe de un acto cuya decisión depende sólo de la libre voluntad del Rey; posteriormente cuando el Monarca se ve obligado a delegar numerosas funciones, firma el Secretario en quien delega que asume responsabilidad exclusivamente ante aquél.

B) En la Monarquía de doble confianza o parlamentarismo dualista propia del siglo XIX y primer tercio del XX, si bien unas veces corresponde al Rey la decisión refrendada, otras muchas la comparte con el Gobierno, aceptando su propuesta, siempre con la posibilidad de retirarle su confianza; luego ya desde el inicio del régimen constitucional varía el contenido del refrendo $y$, en muchos casos, se apoya en una ficción jurídica. Tanto en uno como en otro supuesto existe un acuerdo de voluntades y es el refrendante quien responde jurídica y políticamente del acto del Monarca que, sin refrendo, carece de validez.

C) Mientras que el Rey es cabeza del Ejecutivo y comparte el Legislativo - a través de la iniciativa y de la posibilidad de veto - se puede entender que todos los actos del Estado dependen de la voluntad del Monarca o, al menos, del acuerdo de voluntad con su Gobier- 
no. Desde el momento en que se inicia el tránsito hacia el parlamentarismo monista, en el que el Rey ordinariamente no decide y asume exclusivamente la función de Jefe del Estado - símbolo de su unidad y permanencia - todos los actos que lleva a cabo por mandato constitucional -en el ámbito de cualquier poder - son imprescindibles pues culminan la voluntad del Estado, pero han de estar refrendados ya que el Monarca es irresponsable.

Ahora bien, si en el ámbito del Poder Ejecutivo continúan siendo decididos por quien refrenda, no sucede así en el de los demás poderes en los que ya no participa de forma decisoria el Ejecutivo; el refrendante, pues, sólo puede asumir la legitimidad constitucional del acto del Monarca porque sólo cubre su irresponsabilidad. Por tanto, el refrendo acredita siempre que el Rey ha actuado conforme a las prescripciones constitucionales y el refrendante asume la responsabilidad por este juicio de legalidad. Sólo cuando el acto refrendado depende de la decisión del Poder Ejecutivo el refrendante puede responsabilizarse también de la oportunidad política de la decisión. 